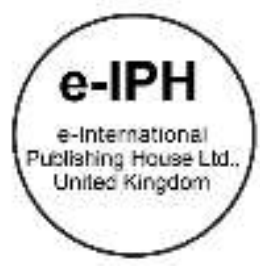

\title{
Determining Controllability Level of Project Issues in Malaysian Landscape Architectural Projects
}

\author{
Adam Aruldewan S.Muthuveeran ${ }^{1}$, Osman Mohd Tahir ${ }^{1}$, Mohd Azren Hassan ${ }^{2}$, Hidayati Ramli ${ }^{3}$ \\ ${ }^{1}$ Department of Landscape Architecture, Faculty of Design and Architecture, Universiti Putra Malaysia, Selangor, Malaysia \\ ${ }^{2}$ Responsive Environmental Development Research Group, Faculty of Architecture, Planning and Surveying, \\ Universiti Teknologi MARA, Selangor, Malaysia \\ 3 Department of Architecture and Built Environment, Faculty of Engineering and Environment, Northumbria University, Newcastle, UK
}

aruldewan@upm.edu.my; osmanmt@upm.edu.my; azren446@uitm.edu.my; hidayati.ramli@northumbria.ac.uk Tel: $+6017-3125446$

\begin{abstract}
The study aims to examine current project issues and the level of controllability in Malaysian landscape architecture projects. The data collection fieldwork was conducted via a semi-structured interview with twenty-four landscape architect professionals in the Klang Valley region. Content and thematic analysis were used to analyse the collected data. Found that project issues are controllable if the project can anticipate and treat them in advance. Nonetheless, issues continue to occur due to insufficient action taken in response to predicted issues affecting project outcomes. The study recommends developing a process for systematically forecasting, evaluating, and treating future issues.
\end{abstract}

Keywords: landscape architecture; project issues; controllability; Malaysia

eISSN: 2398-4287@ 2021. The Authors. Published for AMER ABRA cE-Bs by e-International Publishing House, Ltd., UK. This is an open access article under the CC BYNCND license (http://creativecommons.org/licenses/by-nc-nd/4.0/). Peer-review under responsibility of AMER (Association of Malaysian Environment-Behaviour Researchers), ABRA (Association of Behavioural Researchers on Asians/Africans/Arabians) and CE-Bs (Centre for Environment-Behaviour Studies), Faculty of Architecture, Planning \& Surveying, Universiti Teknologi MARA, Malaysia.

DOI: https://doi.org/10.21834/ebpj.v6i18.3053

\subsection{Introduction}

Landscape architecture projects are viewed as dynamic, with subjective outcomes and a range of challenges resulting from the projects' inherent uncertainty and complexity, resulting in multiple issues. As a result of this scenario, the project's processes, environment, and stakeholders all contribute to the project's failure. As a result, issues must be anticipated and addressed before hurting the project's outcome. Malaysia landscape architecture projects are a subset of the construction industry, which is recognised for a variety of project issues, most notably safety, financial viability, technical proficiency, and environmental stewardship (Hasan et al., 2018; Kurzi \& Schroth, 2018; Marmaya \& Mahbub, 2018; Mohit, 2018; Sani et al., 2018; Shafie et al., 2018; Shamsudin \& Majid, 2019; Thani et al., 2017; Wena et al., 2017). In Malaysia, landscape architecture projects frequently face several difficulties, including insufficient human resources, insufficient skills and expertise, a lack of knowledge, a limited budget, a lack of interest, insufficient tools and equipment, poor quality planting materials, insufficient landscape personnel training, and a lack of civic awareness and attitude (Ackerman et al., 2019; Hussain \& Byrd, 2012; Wang, 2018; Yang et al., 2016)

These risks become project issues, affecting the project's quality, cost, schedule, scope, and objectives (Farooq et al., 2018; PMI, 2017). Preliminary observations indicate that landscape architects can anticipate project issues as practitioners of landscape architecture. The practitioner's knowledge base must be extended to meet the scope of practice, which encompasses all phases of work during the

eISSN: 2398-4287C 2021. The Authors. Published for AMER ABRA cE-Bs by e-International Publishing House, Ltd., UK. This is an open access article under the CC BYNCND license (http://creativecommons.org/licenses/by-nc-nd/4.0/). Peer-review under responsibility of AMER (Association of Malaysian Environment-Behaviour Researchers), ABRA (Association of Behavioural Researchers on Asians/Africans/Arabians) and cE-Bs (Centre for Environment-Behaviour Studies), Faculty of Architecture, Planning \& Surveying, Universiti Teknologi MARA, Malaysia.

DOI: https://doi.org/10.21834/ebpj.v6i18.3053 
development of a project (Hasan et al., 2018). Additionally, they can recommend control measures to avoid anticipated project issues. Regardless of their ability, project issues continue to occur due to ineffective problem-solving. Landscape architecture projects are a landscape architectural firm's primary source of revenue. Failure to meet project objectives will harm the firm's financial performance, operations, culture, and business reputation. Understanding the controllability of current project issues is critical for the project practitioner to plan necessary actions to manage and control these project issues in the future (S.Muthuveeran et al., 2020). Landscape architecture projects are viewed as dynamic, with subjective outcomes and various challenges resulting from the projects' inherent uncertainty and complexity, which inevitably results in multiple issues. As a result of this scenario, the project's processes, environment, and stakeholders all contribute to the project's failure. As a result, issues must be anticipated and addressed before harming the project's outcome. On the other hand, this project addresses issues of controllability directly related to Malaysian landscape architecture projects that have received little attention in the literature.

Thus, this study aims to examine project issues and the level of controllability in Malaysian landscape architecture projects. The objectives to accomplish are as follows: 1) to investigate the ability to predict project issues that occurred, 2) to determine the action taken to address predicted project issues, and 3) to evaluate potential strategies that could be used to prevent project issues from occurring again.

\subsection{Literature Review}

\subsection{Definition of Project Issues}

The definition of project issues varies according to the project's scope and industry. Previously, PMI defined an issue as "A point or matter that is in question or in dispute, or a point or matter that is not settled or under discussion or over which there are opposing views or disagreements" (PMI, 2004, p. 363). Baker (2007, p. 3) defines an issue as "a gap between your actions and stakeholder expectations". Meanwhile, the Office Of Government Commerce (OGC) defines an issue as "a relevant event that has happened, was not planned, and requires action" (OGC, 2009, p. 98).

Consequently, PMI defines a project issue as "A current condition or situation that may have an impact on the project objectives" (PMI, 2017, p. 709). PMI's definition is similar, in substance, to that used within Projects In Controlled Environments (PRINCE2), which defines an issue as "A relevant event that has happened, was not planned, and requires management action. It can be any concern, query, request for change, suggestion or off-specification raised during a project. Project issues can be about anything to do with the project" (PRINCE2, 2017, p. 376). Meanwhile, the UK's APM takes a slightly different view, citing an issue as "A threat to the project objectives that the project manager cannot resolve. Issues should be differentiated from problems, which are concerns that the project manager has to deal with on a day-to-day basis." (APM, 2006, p. 48).

In summary, this research defines a project issue as any situation or event that has harmed the project's ability to accomplish its objectives. It consists of a disconnect between the project's output and stakeholder expectations. Stakeholders include all project parties impacted by the project's outcome, including the serving professional landscape organisation.

\subsection{Project Issues and Risk}

The terms "issues" and "risk" should not define interchangeably. According to the Project Management Body of Knowledge (PMBOK), an issue is a past event or condition that has impacted or is currently affecting the project's objectives. Meanwhile, risk can be defined as an uncertain event or condition that affects the project's objectives, either positively or negatively (PMI, 2017). Issues are certain because they have occurred, whereas risks are uncertain. After all, an event may not occur (APM, 2006). An issue is an occurrence, impediment, or difficulty. A risk is a possibility of suffering a loss (Spacey, 2016).

The distinction is that issues are typically managed in a "present-focused" manner, whereas risks are managed in a "future-focused" manner. Issues are unavoidable because they have already occurred, whereas risk involves an element of uncertainty. Nonetheless, both issues and risks affect a project, which is why they must be managed.

\subsection{Controllability of Project Issues}

According to PMI (2004, p. 238), "a risk may have one or more causes and, if it occurs, one or more impacts". One cause results in a single risk, which may have only one effect, though the reality is far more complex (Bugayenko, 2019; Hillson, 2018). As illustrated in Figure 1, risk meta-language effectively distances risk from its cause and effect (PMI, 2009, p. 29).

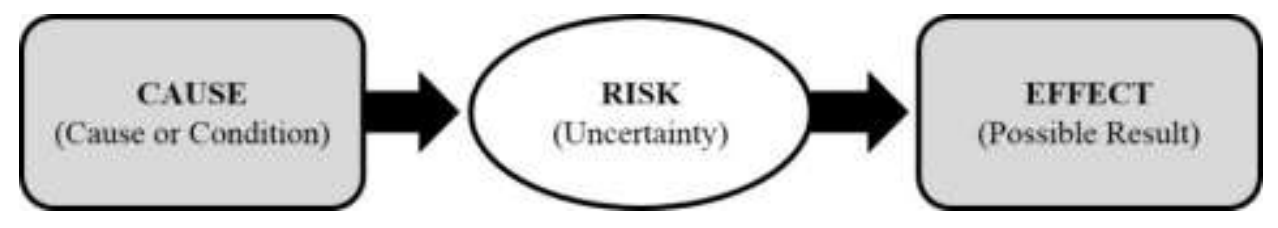

Fig. 1. Cause, risk, and effect

(Source: Extracted from PMI, 2009, p. 29) 
A cause is defined as an observable fact about the project's difficulties or surrounding environment. At the same time, the risk is an unknown that, if it occurs, could harm a project's objective (Hillson, 2018). The result of risk is referred to as project issues. Issues are relevant in the context of risk because "a project risk that has occurred can also be considered an issue" (PMI, 2009, p. 275). The comparison of risk and issues demonstrates that project issues can be mitigated by proactively managing risk (Baker, 2007).

As a result, project issues are controllable to avoid them. Issues can be managed more effectively if they are addressed sooner. Identifying and documenting issues will be a future lesson learned for the project (PMI, 2017). A project manager can take effective action if they anticipate the issues that arise due to a lesson learned effective strategy.

\subsection{Methodology}

The research methodology employed exploratory case analysis. The study follows a four-stage procedure, as illustrated in Figure 2: a preliminary study, data collection, data analysis, and reporting. First, a preliminary study is conducted to ascertain the study's context, the need, the gap, and the study's objectives. Second, data were gathered through a semi-structured interview with twenty-four professional landscape architects in the Klang Valley. Open-ended interview questions were pre-tested and asked in the form of an 'aide-memoire' to give respondents leeway and freedom to respond (McNamara, 2017), keeping with the exploratory study. Audio recordings and project documents were logged, the transcribed text, and documented and organised research software, ATLAS.ti version 8.4.25. Thirdly, content analysis establishes codes, categories, and themes (Mayring, 2014).

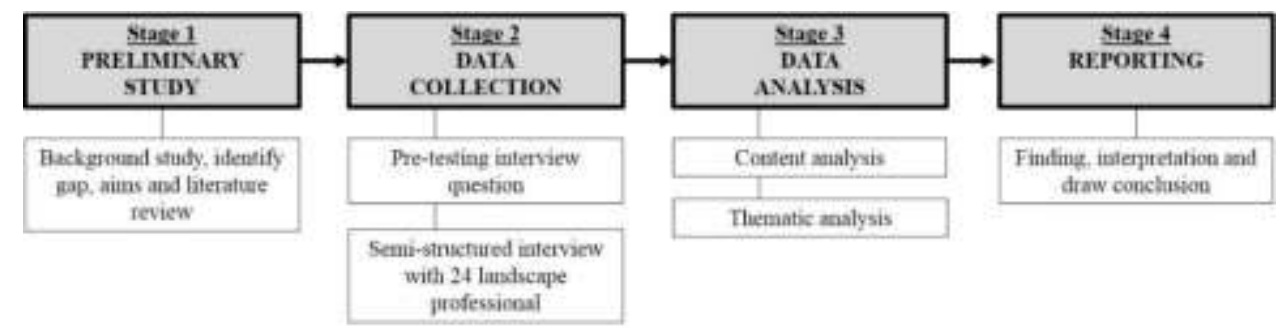

Fig. 2: Study procedures

Additionally, a thematic analysis was used to interpret and map the themes. The analysis entails delving into the relationship between the categories and the theme, identifying patterns, and mapping out an interpretation (Maguire \& Delahunt, 2017). Finally, the findings and interpretations are discussed concerning occurred project issues and forecasted project risk. The conclusion is derived from the research's objectives.

Table 1. Interviewees information

\begin{tabular}{|c|c|c|c|c|c|c|}
\hline \multirow[b]{2}{*}{ Interviewee } & \multirow{2}{*}{$\begin{array}{l}\text { Interviewee's } \\
\text { Position }\end{array}$} & \multicolumn{2}{|c|}{ Interviewee's Background } & \multicolumn{3}{|c|}{ Interviewee's Organisation Background } \\
\hline & & Education & a Years of Experience & ${ }^{b}$ Years Established & $\begin{array}{c}{ }^{c} \text { Headcount } \\
\text { Size }\end{array}$ & ${ }^{d}$ Total Ongoing Project \\
\hline L01 & Director & Abroad & Expert & Established & Small & Medium \\
\hline L02 & Project Director & Local & Intermediate & Established & Small & Medium \\
\hline L03 & Director & Abroad & Expert & Established & Small & High \\
\hline L04 & Director & Local & Expert & Established & Small & Medium \\
\hline L05 & Principal & Local & Intermediate & New & Small & Low \\
\hline L06 & Director & Local & Expert & Established & Small & Low \\
\hline L07 & Director & Local & Intermediate & New & Micro & Medium \\
\hline L08 & Director & Local & Intermediate & New & Micro & Low \\
\hline L09 & Director & Abroad & Expert & New & Small & Low \\
\hline L10 & Director & Abroad & Expert & Intermediate & Small & Medium \\
\hline L11 & Associates & Local & Intermediate & Established & Small & Medium \\
\hline L12 & Head of Contract & Local & Intermediate & New & Small & Medium \\
\hline $\mathrm{L} 13$ & Director & Abroad & Expert & Intermediate & Small & Low \\
\hline L14 & Director & Local & Intermediate & New & Small & Medium \\
\hline $\mathrm{L} 15$ & Director & Local & Expert & Established & Small & Medium \\
\hline L16 & Director & Local & Intermediate & Intermediate & Micro & Medium \\
\hline L17 & Principal & Local & Intermediate & Intermediate & Small & Medium \\
\hline L18 & Director & Local & Intermediate & New & Micro & Low \\
\hline L19 & Principal Director & Abroad & Expert & Established & Small & Medium \\
\hline $\mathrm{L} 20$ & Director & Local & Intermediate & New & Small & Medium \\
\hline $\mathrm{L} 21$ & Director & Abroad & Expert & Established & Small & Medium \\
\hline $\mathrm{L} 22$ & Managing Director & Local & Expert & Established & Small & Medium \\
\hline $\mathrm{L} 23$ & Director & Local & Intermediate & New & Micro & Low \\
\hline L24 & Director & Local & Intermediate & Intermediate & Small & Medium \\
\hline
\end{tabular}




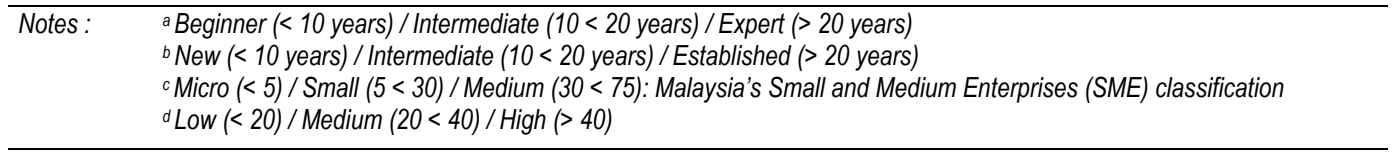

Twenty-four interviewees were selected using predetermined sampling criteria from the landscape architecture organisation. They worked for landscape architecture firms and were licenced landscape architects. They held managerial and decision-making positions in their current organisation, indicating that they influenced policy and practice on the ground. All interviewees possessed a minimum of ten years of industry experience. They had worked on a range of project sizes, locations, and scopes as part of a complete cycle of landscape projects in an urban area in Malaysia's Klang Valley. Each interviewee was assigned an alphanumerical code (L01-L24) to facilitate identification, and the information about each interviewee is listed in Table 2.

\subsection{Findings}

\subsection{Occurred Project Issues}

Interviewees were asked for their perspectives on issues arising from the project challenges they faced. The research obtained 79 coded project issues from the interview feedback and classified them into six affected project objectives depicted in Figure 2

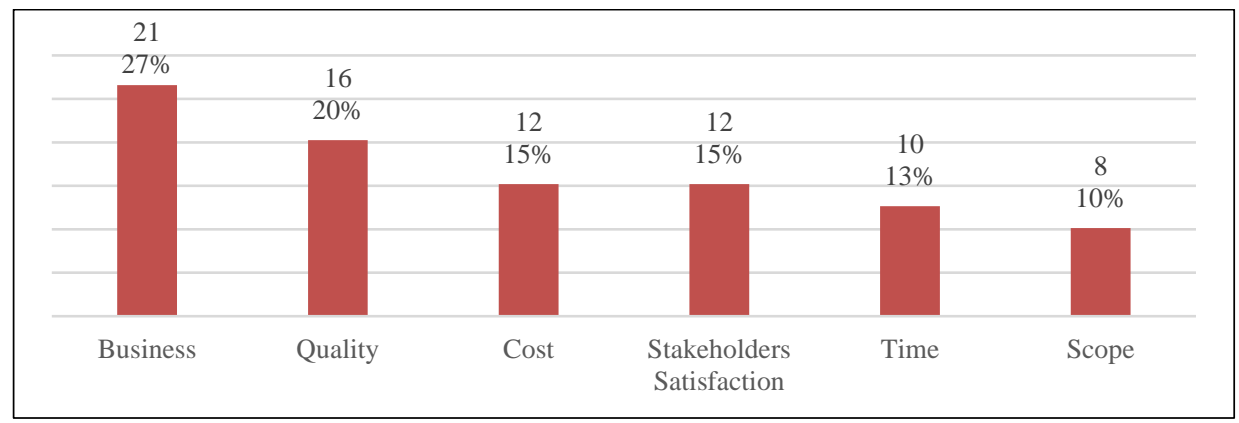

Fig. 2. Summary of affected project issues

The study determined that the most critical issues affect the business objective. Constant design changes, a damaged business reputation, disruptions in internal operations, and demotivated project teams are the most common issues impeding the achievement of business objectives. Meanwhile, substandard contractor work, planting damage, and material misspecification impact the most objective quality. For the cost objective, the most significant causes are unpaid fees to the landscape architect for additional work and design changes. Finally, the scope objective is impacted by extensive Variation Orders (VO) and clients' constant design and planning changes.

\subsection{Predictability of Occurred Project Issues}

Interviewees were questioned about their ability to predict the 79 issues that occurred during the project. The results are classified into predicted and unpredicted categories, as illustrated in Figure 3.

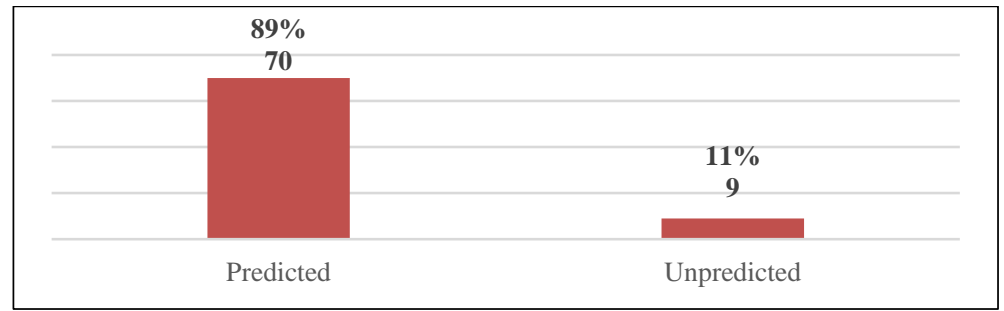

Fig. 3. Predictability of the occurred project issues

The findings indicated that of the 79 project issues, interviewees indicated that $70(89 \%)$ could be predicted in advance. L15 stated, "project issues could be anticipated based on extensive research...require experience of project team members" and similarly mentioned by L03, L13, and L23. Surprisingly, technical issues were quickly predicted, such as budget, technology, workmanship, and scope changes. The issues predicted based on feedback from contractors (L03, L20), team members' experiences (L04, L05, L15, L19), a competent project team (L02, L05), team project meetings and discussions (L05, L06), and forecasting (L06, L19). According to L13, "most project issues can be predicted as early as the project's initiated". L21 mentioned that "project issues should be predicted early in the project's lifecycle", further agreed by L05, L10, L11, and L24. L10 added, "to resolve them before they negatively impact the project's outcome". L11 emphasised, "...it is important to devote time at the initial stage of the project lifecycle because additional project information is required to forecast project issues". 
Only 9 (11\%) of the 79 issues that occurred were unexpected and unanticipated. L04, L07, L09, L11, L13, L14, L16, L17, and L21 asserted that environmental impact, site conditions, new product application, team member turnover, economic instability, design market trend, price fluctuation, social-political climate, project members' personalities, and payment delay were hardly predictable. According to L08, "issues involving subjective matter, such as human, socio-cultural, and environmental ramifications, are difficult to forecast". L17 further added, "landscape scope which requires design input and interaction with the environment, is more subjective than engineering projects... which are objective, resulting in a high level of uncertainty and unexpected incidents".

Most project issues were anticipated based on the project managers' experience and ability to forecast. Technical issues are objective, requiring technology, engineering input, and a predictable scope. On the other hand, intangible issues involving the environment, design, and human personality are more challenging to predict, potentially satisfying stakeholders.

\subsection{Treatment Action for the Predicted Project Issues}

Interviewees were questioned about their approach to treating the 70 predicted issues. The research discovered three distinct behaviour patterns among interviewees regarding the predicted issues, as depicted in Figure 4.

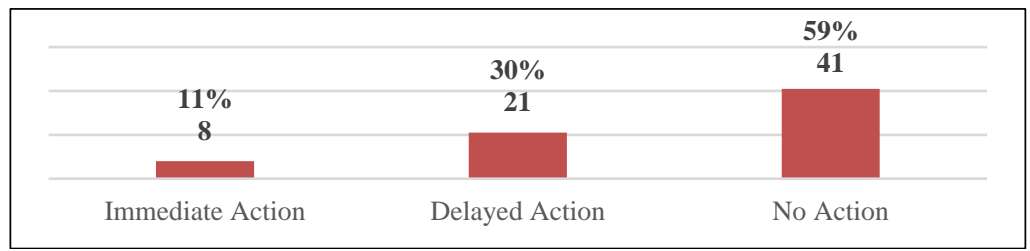

Fig. 3. Treatment action taken over the predicted issues

Only eight (11\%) predicted that issues would be addressed immediately. The actions taken were primarily directed at avoiding the predicted issues. L09 suggests "reducing the scope and simplifying the design", similarly mentioned by L15. Others reduced the servicing effort (L04, L12) and revised the service agreement (L09, L12). L11 highlight "establishing a contingency fund to tackle the issues", whereas L15 suggest "altering the project's operation process", and L22 circumvented the issues by "redistributing the scope to vary relevant project parties".

Second, $21(30 \%)$ predicted issues were delayed action by treating them later when they were about to occur. The majority of the actions focused on mitigating the impact of the project's issues. These include negotiating with the client to obtain additional funds and time allowances (L02, L19); monitoring, documenting, and reporting to protect the consultant (L02, L03, L20, L21); improving communication (L11); and enhancing the client-consultant relationship (L10). When dealing with contractors, mitigation actions are taken to mitigate the impact of the issues by transferring liability to contractors and suppliers (L02, L03) and monitoring the contractor (L06, L08, L09, L14, L17, L24). L22 acted by "mitigate the consequences of the issue by revising the contract...including change operational procedure".

Third, the majority, $41(59 \%)$, predicted the issues but took no action. They delegated day-to-day operations to the project team. This action is due to interviewees lacking alternative options due to various factors. L07 expressed, "no choice to take ownership of the issues...to maintain a relationship with paying client...to survive in business", similar reason by L01 and L06. Others reason for not acting, including compulsory local authority's instruction (L17), the client's instruction (L08, L10, L18, L19, L23), and due to a time constraint (L14, L16). Some predicted issues were left unresolved because the project manager believed they could be resolved through the existing process (L01, L06, L08, L24). L19 asserted, "these predicted issues were anticipated and will have little impact on the project's overall outcome...so no necessary action taken for now". L09, L17, and L24 support this statement. Meanwhile, L02 admitted that "they were aware of the predicted issues but neglected to address them". L05, L14, and L20 opted not to take nor immidiate action when they initially predicted the issues.

The reviewed project issues are certain to occur due to the project's preference for inaction despite its ability to predict previous issues. Delayed action mitigates the consequences of the issues but does not eliminate them. The effective reaction of immediately addressing the predicted issues was determined not to be the preferred course of action. This scenario explains why project issues continue to occur.

\subsection{Suggested Treatment Strategy for the Predicted Project Issues}

The emerging finding indicated that interviewees could express a potential treatment strategy for the project's issues. Their responses are classified into four distinct risk management strategies (PMI, 2017): avoidance, mitigation, transfer, and acceptance of the issues depicted in Figure 5. 


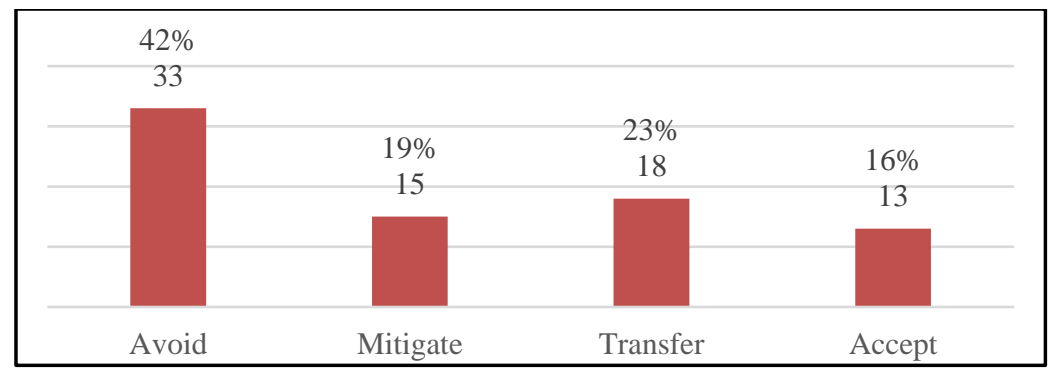

Fig. 4. Suggested treatment strategies for occurring project issues

According to interviewees, avoiding project issues is the preferred course of action (42\%). This strategy was chosen when confronted with project issues affecting the organisation's cost, schedule, and scope. When it comes to project quality issues, the preferred strategy is to transfer $(23 \%)$ the liabilities to other parties. This action is interpreted as the contractor's and supplier's quality of work. As a result, the interviewees shifted the blame to them.

Meanwhile, accepting (16\%) project issues is the preferred course of action when the issues involve stakeholder dissatisfaction. The strategy was used when project issues were unavoidable; no options for mitigating the impact existed, and the issues were not transferable to others. Given how ambiguous and difficult it is to manage stakeholder dissatisfaction, this action is understandable. As a result, the interviewees allowed for project issues while closely monitoring them and preparing for contingencies.

The interviewees may suggest effective treatment strategies for the issues by preventing them, mitigating their effects, or transferring them to minimise their consequences. It contradicts the initial action treatment discussed in subsection 4.3 that they chose to do nothing in the face of predicted problems. Further research is recommended to ascertain the reasons for this phenomenon of divergent actions.

\subsection{Discussion}

Generally, project issues can be avoided if the project can anticipate and treat them in advance. This conclusion was confirmed through in-depth interviews with landscape professionals. The prediction and treatment actions (refer to subsections 4.2 and 4.3) and suggested treatment strategies (refer to subsection 4.4) for the actual project issues are summarised in Figure 6.

In general, the project issues were predictable regarding the encountered project challenges and identified stakeholder factors. The research discovered that interviewees predicted $89 \%$ of project issues in advance. Despite their ability to predict problems in advance, they did not resolve them. Only $11 \%$ of anticipated issues are addressed immediately, as suggested by the project manager. Over $59 \%$ of the predicted issues were not addressed. It was allowed to occur and were left to the project operation team to resolve.

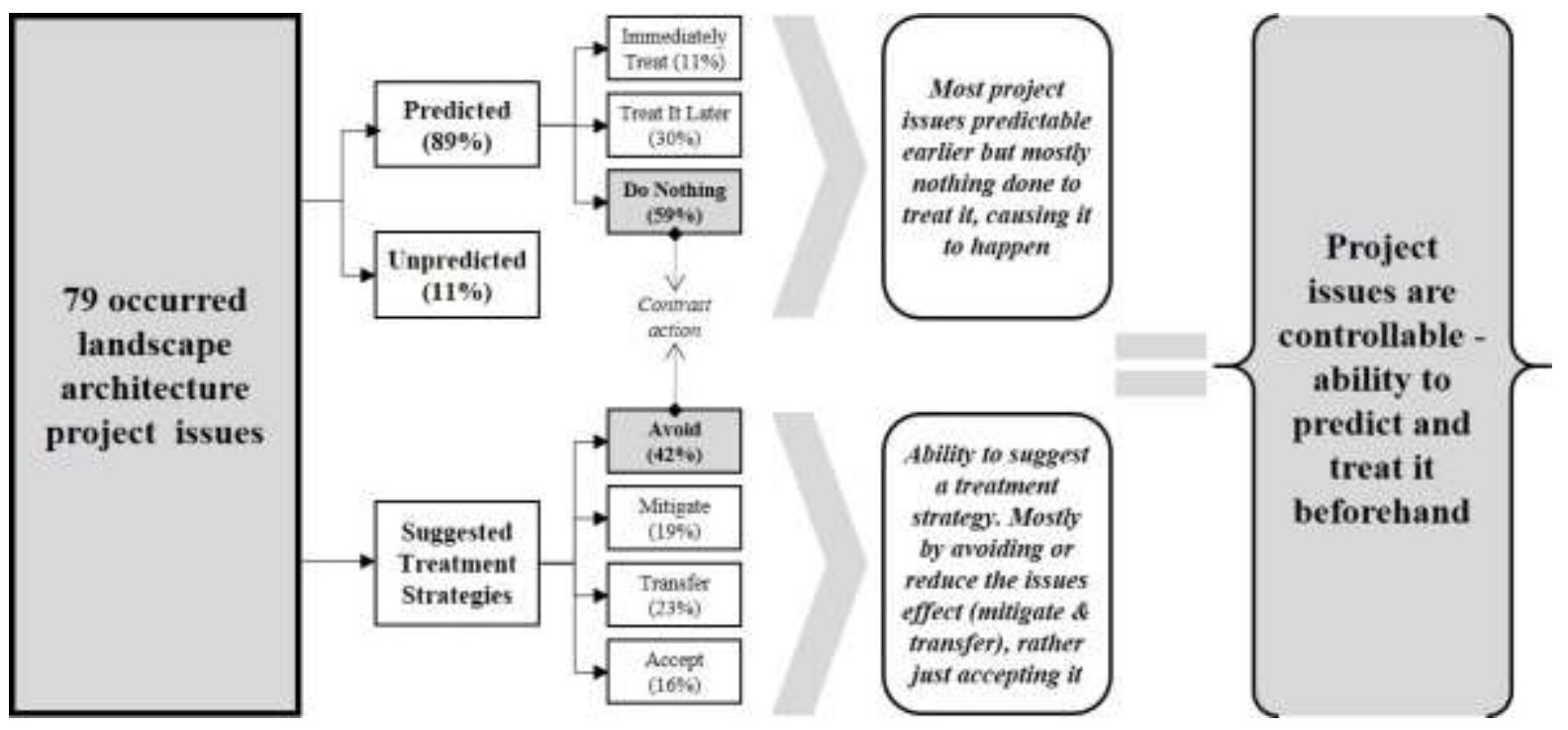

Fig. 5. Controllability of project issues

Additionally, the projects suggested a treatment strategy for each of the issues, demonstrating their capacity to take immediate action rather than inaction. Effectively, $42 \%$ suggested avoiding the project's issues to eliminate them. Another option is to mitigate the issues' impact by either mitigating their consequences (19\%) or transferring their liability (23\%) to others. Only $16 \%$ suggested resolving project issues through contingency plans.

The interviewees unanimously agreed that the project issues are controllable. The findings demonstrate that landscape architecture projects are controllable by predicting and suggesting effective treatment strategies to manage the issues in advance. This finding corroborated the preliminary study findings and confirmed by Hillson (2018) and Spacey (2016), posit that project issues are controllable 
by early prediction, strategising a treatment solution and implementing the strategy effectively. However, the current project culture signifies that despite their ability to predict project issues, no immediate action is taken to treat the issues and mostly leave it to the project operation team to handle them. Adding to this phenomenon, despite the project ability to suggest an effective treatment action by avoiding, mitigating and transferring the issues, this strategy was not implemented well during the project progression. This move caused project issues to happen repeatedly and impacted project performances. Bugayenko (2019), Hillson (2018) and PMI (2017) all concurred, stating that project issues are manageable through proactive risk management. Currently, the project managed with more to issue-focused rather than risk-focused.

\subsection{Limitation Of Study}

The following are the study's limitations. First, the study limited the case study interviews to landscape architecture practitioners, but this was not intended to diminish the significance of other practitioners' perceptions. Second, the case project issues centred on a preference for urban landscape architecture as a context; no other environment was chosen. Thirdly, the study focused on project management within the context of the landscape project lifecycle process, from inception to handover, but not on the entire project lifecycle.

\subsection{Conclusion \& Recommendations}

The study examined the projects' ability to prevent and treat project issues in advance by examining their ability to predict and treat issues. Most project issues were anticipated by thoroughly reviewing the project's challenges and thoroughly understanding the stakeholder factor during the project's early stages. Despite the project's ability to recommend effective treatments, most anticipated project issues were not addressed due to inevitable roadblocks. The projects took no action to address the anticipated issues, and it was left to project operations to resolve them later. In summary, the project issues could have been controlled before their occurrence but were allowed to occur. It was compromising the project's objectives due to inadequate or non-treatment before the occurrence of the issues.

This study strengthens lesson learned knowledge regarding the controllability of project issues, improve project practitioners work culture and preparedness for future endeavours. Thus, the study recommended that issues be controlled earlier by establishing a systematic process for predicting potential project issues, assessing their consequences, and treating them systemically to achieve the project's objective. This systematic process is referred to as risk management. Risk management should improve control over project issues in advance by identifying, assessing, and treating them early. This application will resolve project issues more quickly and more manageable. Controlling project issues enables the achievement of project objectives, thereby enhancing project performance. It will directly enhance the landscape environment to improve dwellers quality of life.

It is recommended that additional research be conducted on risk management practises in landscape architecture projects. Landscape architecture project practitioners must manage risk to effectively minimise project issues in the future.

\section{Acknowledgement}

We are grateful to Geran Putra - Inisiatif Putra Siswazah (GP-IPS), Universiti Putra Malaysia, for financial support for this study (Project Number: GP-IPS/2018/9617500).

\section{References}

Ackerman, A., Cave, J., Lin, C. Y., \& Stillwell, K. (2019). Computational Modeling For Climate Change: Simulating And Visualizing A Resilient Landscape Architecture Design Approach. International Journal of Architectural Computing, 17(2), 125-147. https://doi.org/10.1177/1478077119849659

APM. (2006). APM Body of Knowledge. In Reprinted 2006, 2007 (twice), 2008 (three times), 2009 (twice) (5th ed.). Association for Project Management. https://doi.org/10.1080/10894160.2010.508411

Baker, E. (2007). You've got way too many issues! PM/囚 Global Congress 2007-North America, 1-6. https://www.pmi.org/learning/library/project-risk-management-issuesmanagement-7267

Bugayenko, Y. (2019). Cause + Risk + Effect. Orsk.com. https://www.yegor256.com/2019/05/14/cause-risk-effect.html

Farooq, M. U., Thaheem, M. J., \& Arshad, H. (2018). Improving the risk quantification under behavioural tendencies: A tale of construction projects. International Journal of Project Management, 36(3), 414-428. https://doi.org/10.1016/j.jproman.2017.12.004

Hasan, R., Othman, N., \& Ismail, F. (2018). Choosing Tree for Urban Fabric: Role of Landscape Architect. 6th AicQoL2018Perhentianlsland, 03-04 March 2018 / E-BPJ, 3(7), 199-207.

Hillson, D. (2018). When is a Risk not Risk? The International Association for Contract \& Commercial Management. https://journal.iaccm.com/contracting-excellencejournal/when-is-a-risk-not-a-risk

Hussain, N. H. M., \& Byrd, H. (2012). Towards a Compatible Landscape in Malaysia: An Idea, Challenge and Imperatives. Procedia - Social and Behavioral Sciences, 35 , 275-283. https://doi.org/10.1016/j.sbspro.2012.02.089

Kurzi, N. S., \& Schroth, O. (2018). Maintenance and Personal Safety in Neighborhood Parks: A literature and case study of MPSJ. Asian Journal of Quality of Life (AjQoL), 
3(13), 107-116. https://doi.org/10.21834/ajqol.v3i13.167

Maguire, M., \& Delahunt, B. (2017). Doing a Thematic Analysis: A Practical, Step-by-Step. The All Ireland Journal of Teaching and Learning in Higher Education, 8(3), 335133514. http://ojs.aishe.org/index.php/aishe-j/article/view/335

Marmaya, E. A., \& Mahbub, R. (2018). Evaluation of Environmental Impact and Risk Assessment Methods of Industrial Buildings in Malaysia. Asian Journal of Quality of Life (AjQoL), 3(13), 39-47. https://doi.org/10.21834/ajqol.v3i13.160

Mayring, P. (2014). Qualitative Content Analysis : Theoretical Foundation, Basic Procedures and Software Solution. Social Science Open Access Repository (SSOAR). https://doi.org/http://dx.doi.org/10.4135/9781446282243.n12

McNamara, C. (2017). Field Guide to Nonprofit Program Design, Marketing and Evaluation (5th ed.). Authenticity Consulting, LLC.

Mohit, M. A. (2018). Quality-of-Life Studies in Natural and Built Environment : Challenges and emerging issues. Asian Journal of Behavioural Studies (AjBeS), 3(10), 147157.

OGC. (2009). An Introduction to PRINCE2: Managing and Directing Successful Projects. The Stationery Office (TSO). www.best-management-practice.com

PMI. (2004). A Guide To The Project Management Body Of Knowledge (PMBOK Guide) (PMBOK (ed.); 3rd ed.). Project Management Institute, Inc. https://doi.org/10.1016/0263-7863(95)00006-C

PMI. (2009). Practice standard for project risk management. In Project Management Institute, Inc. (PMI). http://app.knovel.com/web/toc.v/cid:kpPSPRM002

PMI. (2017). A Guide To The Project Management Body Of Knowledge (PMBOK Guide) (PMBOK (ed.); 6th ed.). Project Management Institute, Inc. https://doi.org/10.1002/pmj.21345

PRINCE2. (2017). Managing Successful Projects With PRINCE2 (6th ed.). The Stationery Office (TSO). www.tsoshop.uk

S.Muthuveeran, A. A., Mohd Tahir, O., Ibrahim, R., \& Abd-Karim, S. B. (2020). Reviewing Risk Process Integration Effectiveness into Malaysia's Landscape Architecture Project Lifecycle. Environment-Behaviour Proceedings Journal (E-BPJ), 5(13), 245-255. https://doi.org/10.21834/e-bpj.v5i13.1991

Sani, J. A., Sharip, N. A. A., Othman, N., \& Hussain, M. R. M. (2018). Relationship between Types of Organization with the Quality of Soft-scape Construction Work in Malaysia. Asian Journal of Quality of Life (AjQoL), 3(12), 137-146. https://doi.org/10.21834/ajqol.v3i12.150

Shafie, F. A., Omar, D., \& Karuppanan, S. (2018). Environmental Risk Evaluation of a Sanitary Landfill using Life Cycle Analysis Approach. Asian Journal of EnvironmentBehaviour Studies (AjE-Bs), 3(8), 89-95. https://doi.org/10.21834/aje-bs.v3i8.282

Shamsudin, N. M., \& Majid, F. A. (2019). Effectiveness of Construction Safety Hazards Identification in Virtual Reality Learning Environment. 8th AcEBs2019Langkawilsland, Malaysia 18-19 Dec 2019 / E-BPJ, 4(12), 375-381.

Spacey, J. (2016). Risk vs Issue. Simplicable. https://simplicable.com/new/risk-vs-issue

Thani, S. K. S. O., Mohamad, N. H. N., \& Abdullah, S. M. S. (2017). Influence of Urban Landscapes to Microclimatic Variances in a Tropical City. Asian Journal of Behavioural Studies (AjBeS), 2(7), 31-41.

Wang, Z. (2018). Evolving landscape-urbanization relationships in contemporary China. Landscape and Urban Planning, 171(December 2017), 30-41. https://doi.org/10.1016/j.landurbplan.2017.11.010

Wena, J., Ismail, F., Hashim, N., \& Romeli, N. (2017). Adaptation Criteria towards Quality Culture for the Malaysian Contractors. 5th AicQoL2017Bangkok, 25-27 February 2017 / E-BPJ, 2(5), 79-83. https://doi.org/10.21834/e-bpj.v2i5.676

Yang, B., Li, S., \& Binder, C. (2016). A research frontier in landscape architecture: landscape performance and assessment of social benefits. Landscape Research, 41(3), 314-329. https://doi.org/10.1080/01426397.2015.1077944 